\title{
Hitting the road to alleviate India's rural doctor shortage
}

I $n$ the shade of a blooming neem tree, revered in India for its healing cproperties, 50-year-old Ramala Marrama waits for relief.

She holds her head with both hands, grimacing as she grabs her stomach, then points to her back - here is where it hurts. The headaches and the backaches have persisted for months, despite long treks to a private hospital, where she was prescribed medications that did not help. The pain torments her, she explains, and she has a household to run.

She is hoping that a new mobile health program, created by the government of the southern Indian state of Andhra Pradesh, will relieve her agony and so she has come to line up on a Saturday morning to see the health care workers in the van that has rolled into Yarragandlapalli, population 2230.

The program is the government's response to an enormous conundrum: what to do about the staggering numbers of villagers like Marrama — an estimated 600000 people in Andhra Pradesh alone - who go untreated every day, when there is an even more staggering shortage of doctors and nurses.

The van, equipped with a few basic medical tools and over-the-counter medications, somehow seems a feeble response. But it is a response in a nation where experts say at least 600000 more doctors and 1 million nurses are needed to achieve the 1:1000 doctorpatient ratio recommended by the World Health Organization. It is a tall order for a country that graduates 30000 new doctors and 45000 nurses annually. It all but makes equitable access to healthcare impossible.

Currently, there are 60 doctors for every 100000 people in India, a significant improvement from the 50:100 000 ratio that existed when India achieved independence in 1947. By comparison, India's Planning Commissions pegged the rate at 209 in Canada and 548 in the United States when it noted last year that the "overriding re-

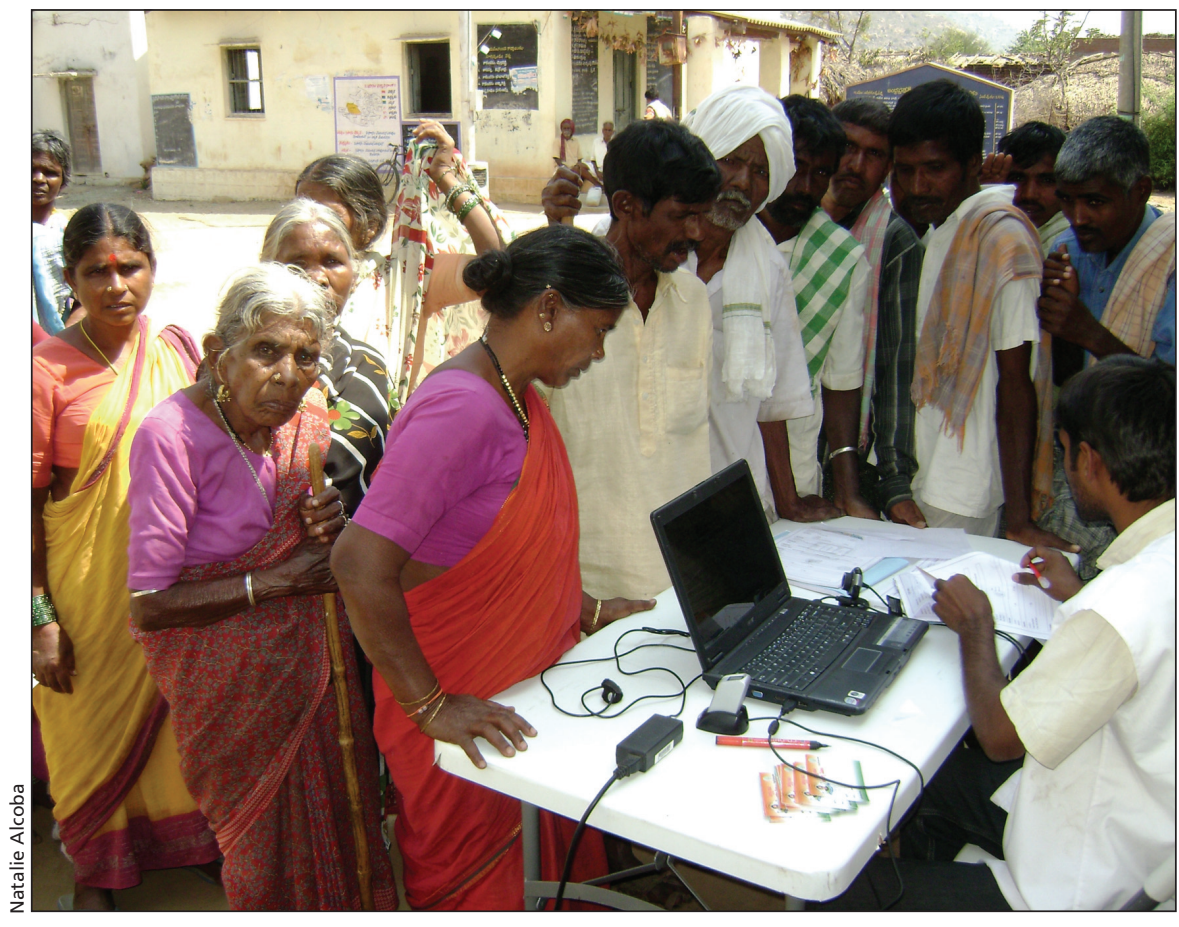

Crowds gather around the patient intake station for the mobile health program.

quirement in the country is for increasing the supply of human resources at all levels, from specialists to paramedical personnel, and to improve their quality."

India has significantly improved health indices like life expectancy, and infant and maternal mortality rates, but it still lags behind other countries in the region.

Redressing rural health disparities, though, has proven to be problematic. While there are state programs like the one in Andhra Pradesh that bring a basic level of care to villagers, and federal funding to train more doctors, as well as the promise of incentives for young doctors who set up their shingles in underserved regions, the gap between urban and rural health services remains wide, and the glacial speed of countrywide schemes designed to even the playing field means many never get the care they need.

The Planning Commission argued that the only way to address the crunch in human resources is to open up medical education "completely for private sector participation and companies being allowed to establish medical and dental colleges just as they have been allowed to open nursing colleges." It's currently projected that the private sector will establish 60 new medical colleges and 250 nursing schools over the next few years.

Yet training more doctors is but part of the solution, as it is becoming increasingly clear that India is in a highly competitive battle with developed countries to retain the services of those newly minted doctors.

"Out of the total number of graduates, $10 \%$ are opting for pastures abroad. The basic fact is that India needs them, and India is not in a position to retain them," says Dr. Vedprakash Mishra, vice chancellor of DMIMS University, a medical college in Nagpur. Indian government figures indicate that 60000 doctors trained in India are now working outside the 
country, including nearly 9000 in Canada. The Indian government has trained $2 \%$ of the Canadian physician workforce and $5 \%$ of that of the US and the United Kingdom.

Moreover, most doctors who remain in India are more inclined to work in major cities, as is the case in Canada.

"The problem is that most doctors don't join their services in the remote and rural areas and that is a major issue of concern. The long-term solution is that the government will have to increase their salaries," says Madhukar S. Chaudhari, director of the National Rural Health Mission in the central state of Maharashtra.

Currently, a public doctor posted in a Maharashtra village earns about 20000 to 25000 rupees a month less than $\$ 500$. They can make more than double that by opening up a private clinic in the city, says Chaudhari.

The federal government hopes to redress some rural health disparities by hiking spending on public health to $2 \%$ of gross domestic product, from $1 \%$, by 2010. In doing so, it has also vowed to place a major focus on rural initiatives, especially the improvement of primary health care. Currently, rural regions are serviced by primary health centres that are staffed by doctors and nurses, when they're available.

There is also a move towards community health insurance schemes that would see villagers contribute a nominal amount of money to a pot, which the sick could then access to pay for private health care.

As well, while several states have compulsory rural medical stints, there has been pressure on the federal government to enact such legislation for all medical students.

Beyond that lie questions of infrastructure. "It's not only more hospitals in the rural areas, but existing hospitals need augmentation, they need better facilities," says Mishra, a member of the executive committee of the Medical Council of India, the governing body of physicians.

The most immediate need, of course, is providing primary care to the millions who need it and to that end, many states have designed "Hospital on Wheels" programs, like that of Andhra Pradesh.

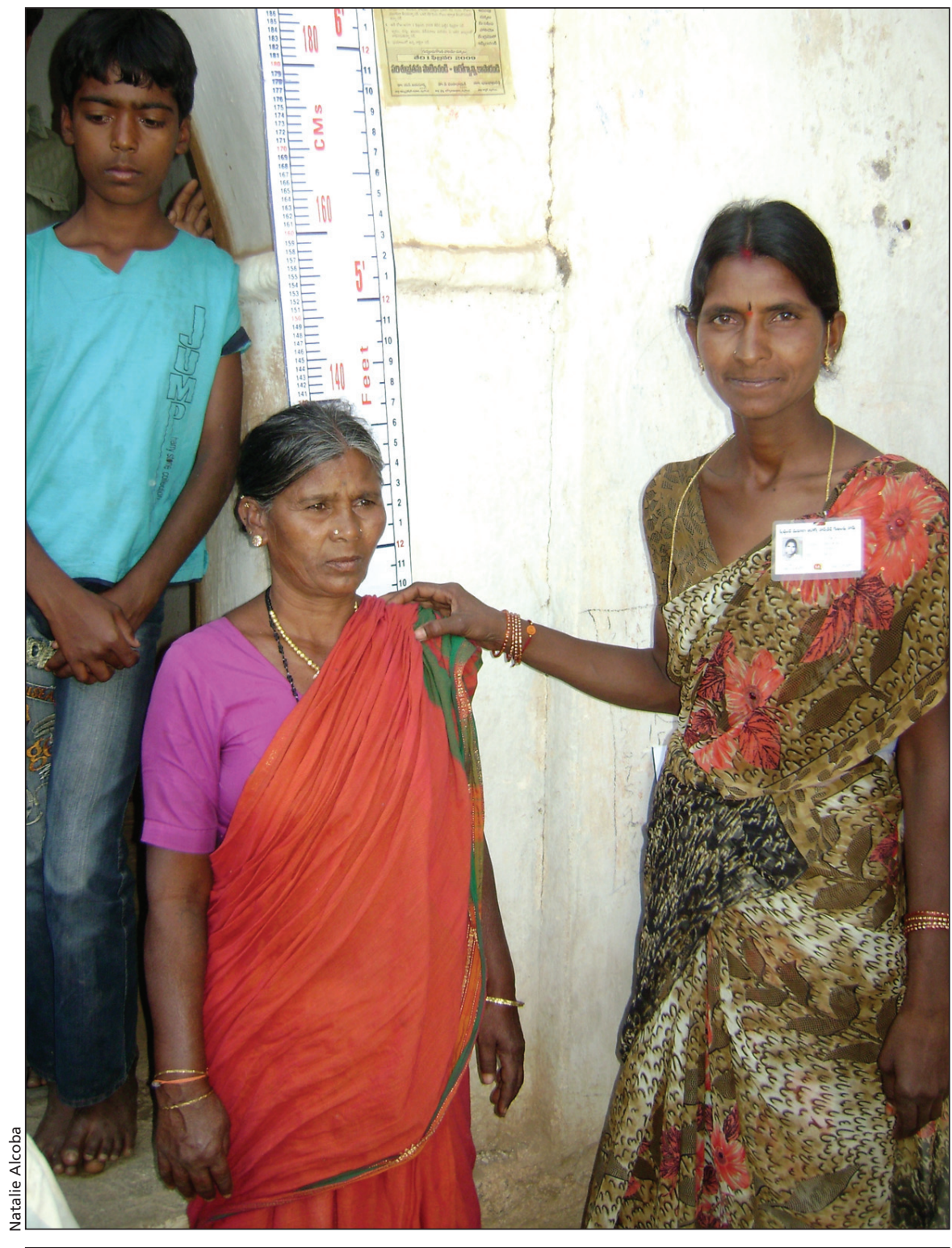

Busereddy Thannama is the designated ASHA, or Accredited Social Health Activist, in Yarragandlapalli. She serves as the village's point of contact for the mobile health program.

The state of Assam, tucked away in northeastern India, has a fully equipped mobile hospital with all the basic equipment that would be found in a primary health centre, including an x-ray, ultrasound machine and electrocardiograph machines. But limited resources mean that the hospital can only visit a village once every 3 months.

"You should be visiting that village in 3 days, so that we actually know whether the patient has improved, but that is not possible," says Dr. J.B. Ekka, director of the National Rural Health Mission in Assam. He adds that the mobile hospital is not a long-term solution to the problem, but "it's better than no health care at all."

The state of Maharashtra is also tendering contracts for vans that will go into the countryside, while in Andhra Pradesh, where $86 \%$ of its 80 million people live more than 3 kilometres away from the nearest hospital, mobile hospitals now operate in all 23 districts.

An inaugural visit typically involves a curious juxtaposition. In Yarragandlapalli, a health worker scanned thumbprints and inputted patient information on a laptop - in a dusty village square. There were 3 other stations: 1 to weigh and check the development 
stages of an infant, 1 to dispense overthe-counter medication, and 1 to take blood samples to test for ailments like diabetes or malaria.

On this Saturday, there is no doctor on board. Rather, the mobile hospital is staffed by health care workers trained to deal with low-level complaints and dispense medication.

One woman in every village is named an "ASHA," which stands for Accredited Social Health Activist. It is not an accidental acronym - in several Indian languages, the word means hope. The village ASHA is the point of contact for anyone who needs help. In Yarragandlapalli, that woman is Busereddy Thannama, a 33-year- old mother of 2 who was deemed a "worthy" candidate by a village elder. It is obvious that villagers trust Thannama. They turn to her to measure their height on a large laminated ruler taped to the wall of a house and they leave footprints on a white scale when she asks.

The program also equips her with a mobile phone, ensuring that villagers have access to a telephone health line that operates out of a call centre in the capital of Hyderabad. The 25000 calls that go through the centre every day are answered by paramedics trained to dispense advice or, if necessary, refer the call to a staff of doctors.

"We believe we are also reducing the pressure on the doctor by introducing skilled paramedics," says Kakani Dharmaraju, head of the call centre. "In countries like India it is a need. Potentially for cost saving purposes it would be a need in other countries, but in India, it is just a basic need."

Thannama describes her task as that of a counsellor. "I tell them that this is what they should do and I tell them the right place to go."

Meanwhile, Ms. Marrama has left the village and returned to her household, before disclosing whether she actually found relief. - Natalie Alcoba, Yarragandlapalli, India

DOI:10.1503/cmaj.090439 